\title{
Effects of Nozzle-Lip Length on Reduction of Transonic Resonance in 2D Supersonic Nozzle
}

\author{
Seoungyoung Shin, Akira Matsunaga, Hiroyuki Marubayashi, Toshiyuki Aoki \\ Department of Energy and Environmental Engineering, Kyhu University, Fukuoka, Japan \\ Email: shszero@gmail.com
}

Received May 28, 2013; revised June 5, 2013; accepted June 12, 2013

Copyright (C) 2013 Seoungyoung Shin et al. This is an open access article distributed under the Creative Commons Attribution License, which permits unrestricted use, distribution, and reproduction in any medium, provided the original work is properly cited.

\begin{abstract}
It is known that the transonic resonance takes place, in divergent section of supersonic nozzle, similarly to the longitudinal acoustic resonance of a conical section with one end closed and the other end open. And the "conical section" is similar to the separation zone between shock wave and nozzle exit in divergent part of supersonic nozzle. The present paper describes an experimental work to investigate a reduction of transonic resonance by change the lip length of 2Dimensional converging-diverging nozzle. In this study, the nozzle pressure ratio varied in the range between 1.4 and 2.2 as shock-containing flow conditions. And a Schlieren optical system was used to visualize the flow fields. Especially, by using a high-speed video camera, we obtained the shock position at that moment. And acoustic measurements were employed to compare the sound spectra level of each experimental case. And it was found that the transonic resonance was decreased when a large separation zone located at the side, where a nozzle-lip attached to nozzle exit additionally. In this case, the amplitude of shock oscillation and wall static pressure oscillation were also decreased.
\end{abstract}

Keywords: Transonic Resonance; Nozzle-Lip Length; Noise Reduction

\section{Introduction}

Supersonic jet noise is frequently encountered in many diverse engineering applications such as supersonic aircraft engine, jet propulsion thrust vectoring, fuel injection for supersonic combustion, soot blower devices, thermal spray devices, etc. In general, it is known that the supersonic jet noise consists of three major components: the turbulent mixing noise, the broadband shock-associated noise, and the screech tones [1]. However, the transonic tone can occur independently of the general noise components at low nozzle pressure ratios when a shock wave occurs within the divergent section of convergentdivergent nozzle without any abrupt area change. Concerning the transonic tone, a great deal of experimental and numerical research of the diffusion of the transonic tone has been carried out. Zaman et al. investigated the characteristics of the transonic tone in various nozzle conditions [2], and provided correlation equations to predict the transonic tone frequency from a collection of data for single round nozzles. Moreover, they showed that transonic tone takes place similarly to the (no-flow) longitudinal acoustic resonance of a conical section with one end closed and the other end open. Accordingly, it is called "transonic tone" or "transonic resonance". How- ever, it is poorly known under what process the transonic tone can occur and how to reduce the transonic resonance in actual flow complicated by shock oscillation and shock wave/boundary layer interaction phenomenon. The objective of this study is to investigate the effects of nozzle-lip length on reduction of transonic resonance in 2Dimensional supersonic nozzle. Especially, it takes account of not only nozzle-lip length but also the location of large separation zone in parallel.

\section{Experimental Procedure}

\subsection{Experimental Apparatus}

This study had conducted in an anechoic test room which is schematically shown in Figure 1. Preliminary acoustic tests show that the test room is anechoic for frequencies above approximately $120 \mathrm{~Hz}$ and the background noise is at about $10 \mathrm{~dB}$. And compressed air is stored in a highpressure tank which has a capacity of $5 \mathrm{~m}^{3}$, and is supplied to the plenum chamber in which a honeycomb system reduces flow turbulence. A convergent-divergent nozzle with a design Mach number of 2.0 was placed into the wall of the plenum chamber. And the supersonic nozzle designed by characteristic method, has throat 
height of $9.6 \mathrm{~mm}$, exit height of $17.2 \mathrm{~mm}(H)$, width of $30 \mathrm{~mm}(\mathrm{~W})$ and the length of divergent section was 46 $\mathrm{mm}(L)$, as shown in Figure 2. The sidewalls of the supersonic nozzle have optical grasses to allow flow visualization by a schlieren optical system. To measure the position of the shock wave in the nozzle-divergent section while the transonic resonance occurs, visualization was performed by schlieren method with high-speed video camera [Photron FASTCAM SA5]. The movie was recorded as the frame rate was 10,000 fps with $5 \mu$ sshutter speed. And measurement time and pixel count are $1.6 \mathrm{~s}$, and $256 \times 512$, respectively. Acoustic measurements were made by using a condenser microphone [Ono-Sokki MI-6420] that has a diameter of 1/4 inch. And the microphone which shown in Figure 3, was located at angles $(\theta)$ of 60 degrees from the jet flow direction, and a radial distance of $516 \mathrm{~mm}$ from the exit of the nozzle $(r / H=30)$. The acoustic signals were analyzed using the FFT analyzer [Ono-Sokki DS0221]. The FFT analysis provided the noise spectra, in the range from 0 to $40 \mathrm{kHz}$, with a frequency bandwidth of $25 \mathrm{~Hz}$. And the pressure measurements were done by setting up the pressure ports at $\mathrm{x} / \mathrm{L}=0.87$ from the nozzle throat, using the semiconductor pressure sensor [TEAC XCS-190]. The sampling frequencies of condenser microphone and semiconductor pressure sensor are the same with $50 \mathrm{kHz}$.

\subsection{Experimental Procedure}

In this paper, the nozzle pressure ratio (NPR) is defined as the ratio of the pressure inside the plenum chamber $p_{0}$ to ambient back pressure $p_{\mathrm{b}}$. According to the one-dimensional analysis for the present nozzle, the correct expansion state at the nozzle exit is obtained at NPR = 7.8. And experiment was carried out for different nozzle pressure ratios from 1.4 to 2.2. And nozzle-lip length was varied to study its effect on the transonic resonance by attaching cuboid tips on the nozzle exit. The tip has $6 \mathrm{~mm}$ height, $30 \mathrm{~mm}$ width and $6 \mathrm{~mm}$ (I) or $12 \mathrm{~mm}$ (I) length. Also the location of large separation zone (or flow direction) was varied at each experimental case. Table 1 shows detail of experimental conditions about all cases. In Table 1, subscript "n", "u", "d" and "ud" mean "no-lip", "upper side", "bottom side" and "both side" attached condition, respectively. And " $U$ " and " $D$ " mean flow direction or the opposite side of large separation zone location.

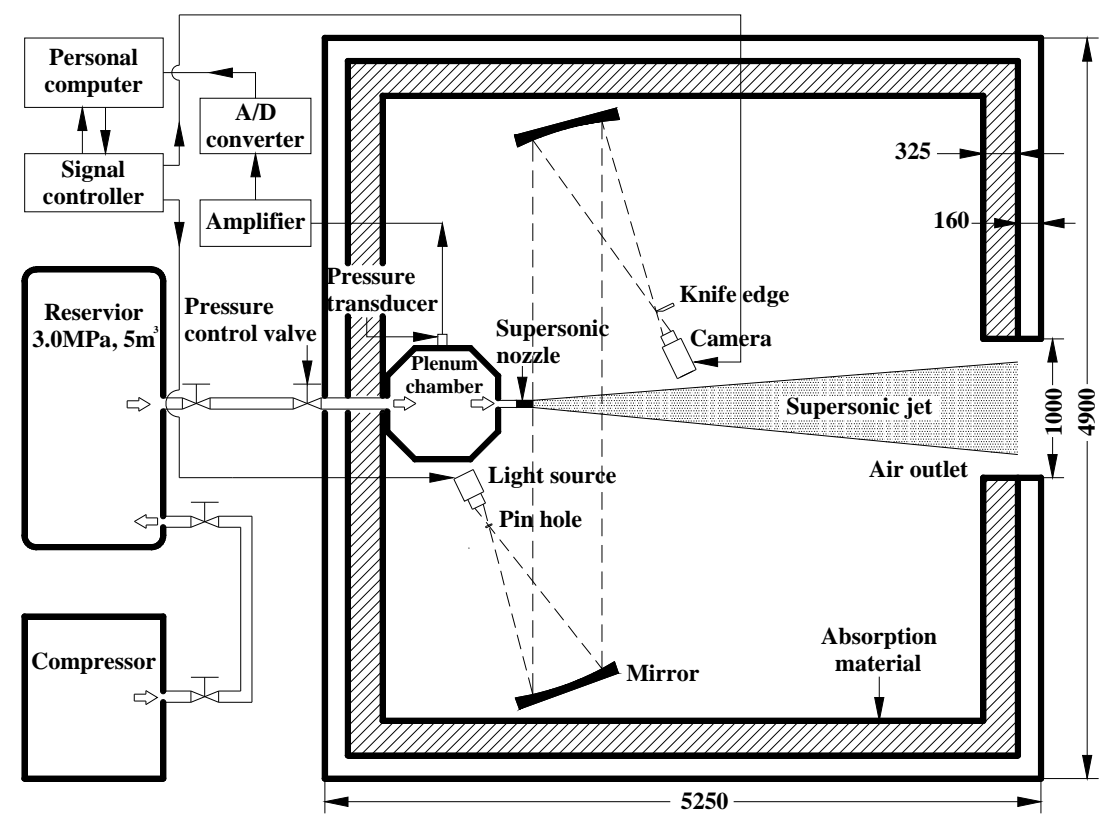

Figure 1. Experimental apparatus and measuring system.

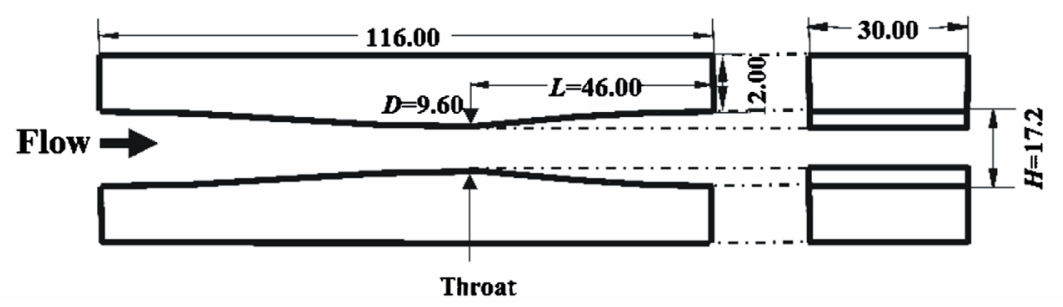

Figure 2. Supersonic nozzle geometry. 


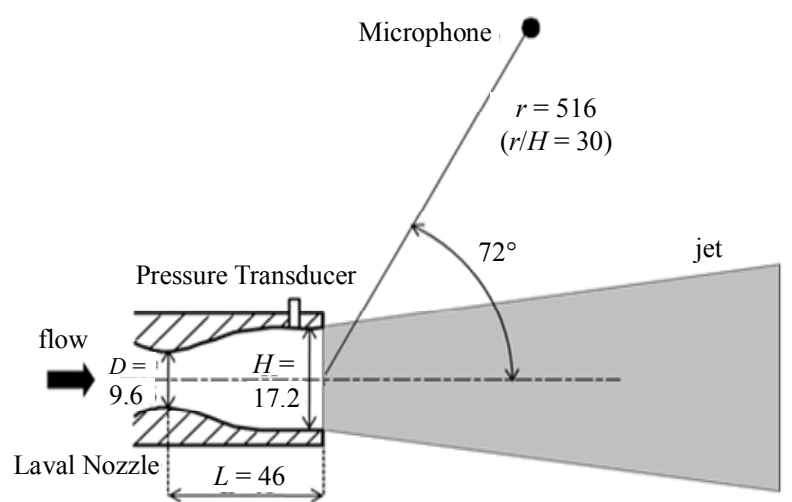

Figure 3. Measurement point of sound pressure level.

Table 1. Experimental sets.

\begin{tabular}{|c|c|c|c|c|}
\hline & \multicolumn{2}{|c|}{$=$} & \multicolumn{2}{|c|}{$\Longrightarrow$} \\
\hline & $6 \mathrm{~mm}$ & $12 \mathrm{~mm}$ & $6 \mathrm{~mm}$ & $12 \mathrm{~mm}$ \\
\hline $\bar{P}$ & 6n-D & $12 n-D$ & $6 u-U$ & $12 \mathrm{u}-\mathrm{U}$ \\
\hline ב & 6u-D & $12 \mathrm{u}-\mathrm{D}$ & $6 u-U$ & $12 \mathrm{u}-\mathrm{U}$ \\
\hline $\begin{array}{l} \\
\end{array}$ & 6d-D & $12 d-D$ & $6 \mathrm{~d}-\mathrm{U}$ & $12 \mathrm{~d}-\mathrm{U}$ \\
\hline 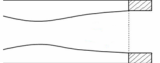 & 6ud-D & 12ud-D & 6ud-U & $12 \mathrm{ud}-\mathrm{U}$ \\
\hline
\end{tabular}

\section{Results and Discussion}

\subsection{Sound Spectra and Tone Frequency}

Figure 4 shows the sound pressure spectra in case of normal nozzle. And the red and blue solid line mean downside and upside flow direction. In Figure 4, there are some peak value of sound pressure level at about 800 $\mathrm{Hz}$ and $2.5 \mathrm{kHz}$ which is known as transonic resonance of stage 1 (solid arrow) and stage 2 (open arrow), respectively. According to Zaman et al., standing one-quarter, three-quarter waves exist between the shock wave and nozzle exit. And the frequency of transonic resonance is proportional to NPR because the shock wave in the divergent section moves to the downstream as the NPR increases, and the distance between the shock wave and nozzle exit shorten. And each difference of sound pressure level between "n-D" and "n-U" is less than $2 \mathrm{~dB}$. In Figure 5, the frequency of the transonic resonance and calculated value by Zaman's empirical formula are plotted with nozzle pressure ratio. As shown in Figure 5, there are some gaps between broken line of Zaman's formula and each transonic tone frequency. However a similar tendency is seen that the transonic tone increases with increasing of NPR.

\subsection{Reduction of Transonic Resonance}

It is shown comparisons of sound pressure level ac-

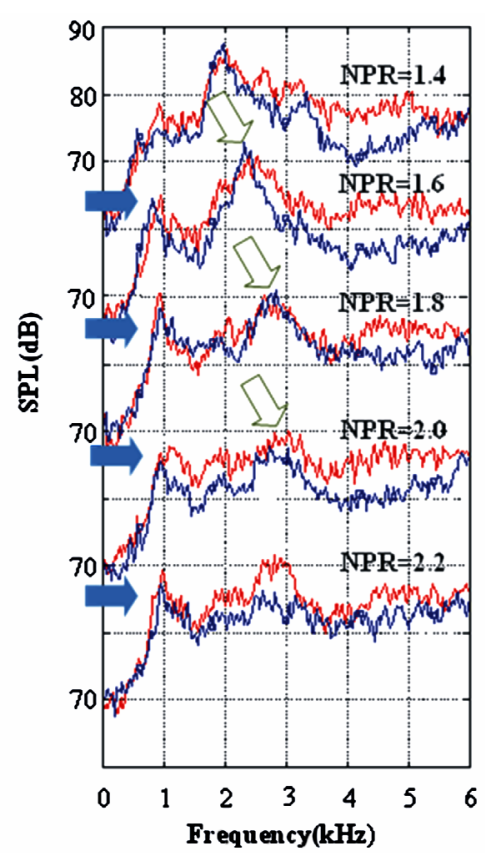

Figure 4. Variation of sound pressure level for n-D and n-U.

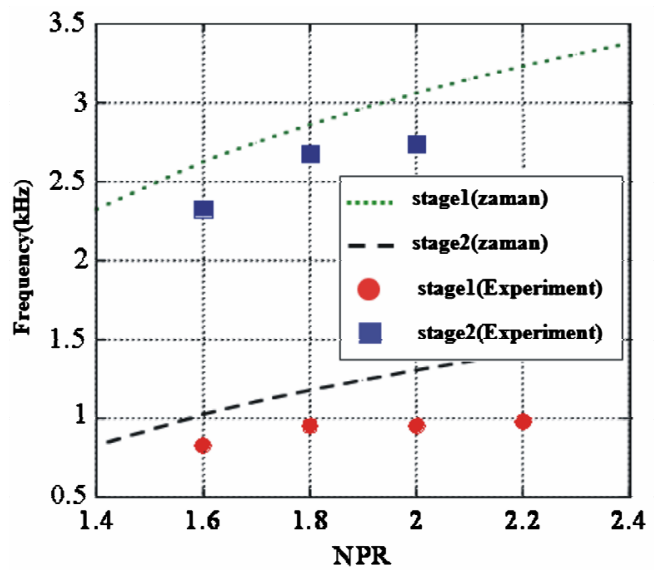

Figure 5. Comparison of transonic tone frequency between experiment and Zaman's empirical formula.

cording to nozzle-lip length and flow direction at 1.8 NPR in Figure 6. And it is clearly shown that the stage1 transonic resonance is reduced at the case of (a), (d), (e) and (f). In case of "d-D" at Figures 6(b) and (c), however, there are little effects of nozzle-lip length. Meanwhile, in Figures 6(e) and (f), the transonic resonance is reduced both cases and each sound pressure spectra are almost same with (a) and (d), respectively. Therefore it can be considered that the effect of reduction is valid for stage 1 when the large separation zone locates at the side of nozzle-lip attached. And effects of reduction are larger at $12 \mathrm{~mm}$ nozzle-lip length than $6 \mathrm{~mm}$. Each amount of transonic resonance reduction is plotted in bar chart in Figure 7. The same tendency like 1.8 NPR reviewed in Figure 6 is shown at every case. That is, the amount of 


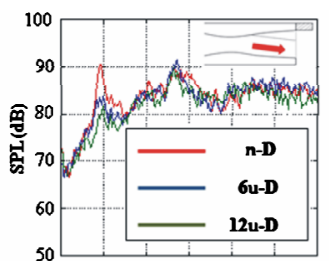

(a)
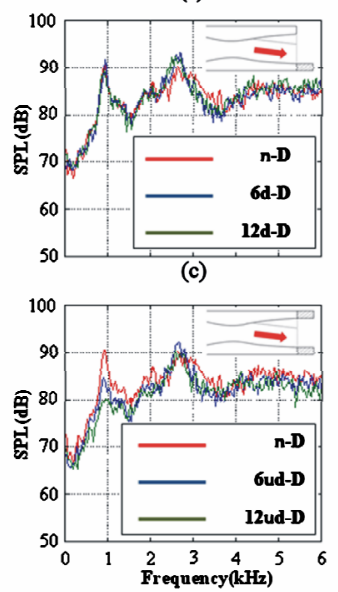

(e)

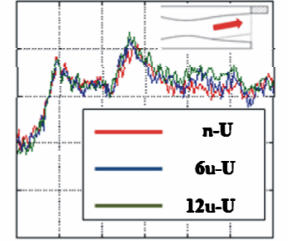

(b)
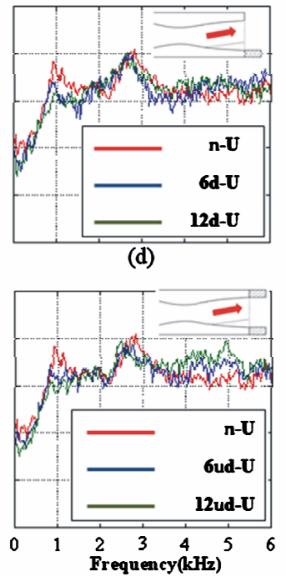

(f)
Figure 6. Comparison of sound pressure level for 1.8 NPR.
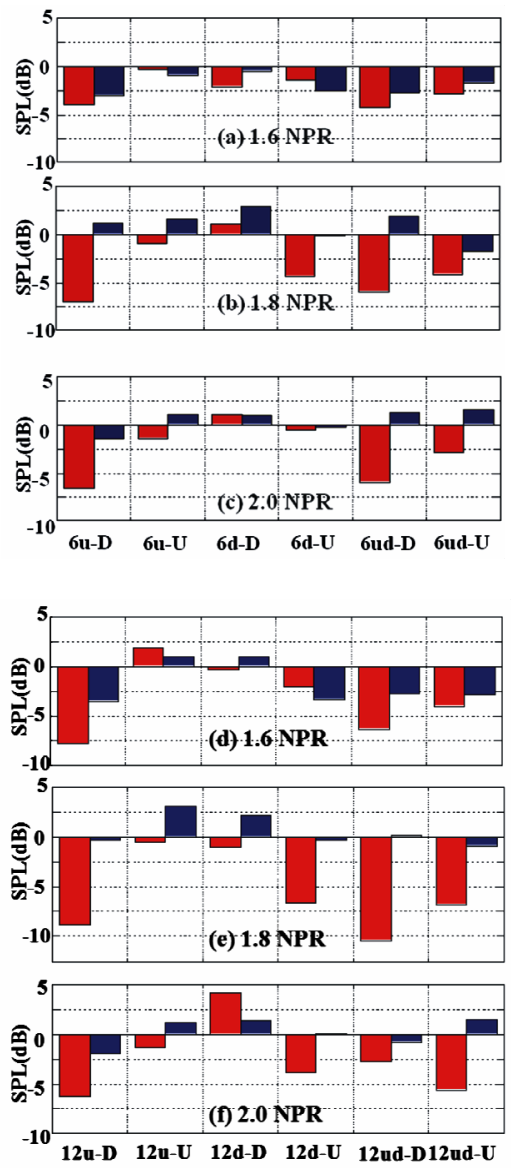

Figure 7. Amount of transonic tone reduction (red bar: stage 1, blue bar: stage 2). tone reduction is remarkable at stagel and larger at longer lip attached in most case. Also, the case of "u-D" and "d-U" have similar tendency to "ud-D" and "ud-U", respectively. Figure 8 shows variation of amount of transonic resonance reduction with various nozzle-lip lengths at 1.8 NPR. At the case of 1.8 NPR, it is clearly shown that the transonic resonance sharply reduced until $0.4 \mathrm{I} / \mathrm{W}$, and gradually reduced. There are some differences between " $u-D$ " and "d-U" but the tendency is almost same at stages 1 and 2 .

\subsection{Wall Static Pressure}

Figure 9 shows the variation of power spectral density of wall static pressure oscillation in case of $12 \mathrm{~mm}$-nozzlelip attached. For the case of the transonic resonance emitting, there are high power spectral density at about 800 $\mathrm{Hz}$ and $2.5 \mathrm{kHz}$, mostly. However, at the Figures 9(a) and (d) which are transonic resonance reduced conspicuously, each power spectral density is gradually distributed. Also the same tendency is found as sound pressure level that the power spectral density of "ud-D" and "ud-U" are similar to "u-D" and "d-U", respectively.

\subsection{Amplitude of First Shock Wave Oscillation}

In Figure 10, Schlieren images are shown for the case of corresponding to the condition of the transonic resonance emitting and $12 \mathrm{~mm}$ nozzle-lip attached. And by analyzing the Schlieren images, the amplitude of first shock wave oscillation was compared with no-lip attached nozzle's results which are shown in Figure 11. From the Figure 11, we can recognize that the amplitude of first shock wave oscillation is also decreased as the transonic resonance reduces.

\section{Conclusions}

In this study, to investigate the effects of nozzle-lip length on transonic resonance reduction in 2-Dimensional supersonic nozzle, experiments were performed in divers conditions which were considered in the location of large separation zone (or flow direction), nozzle-lip
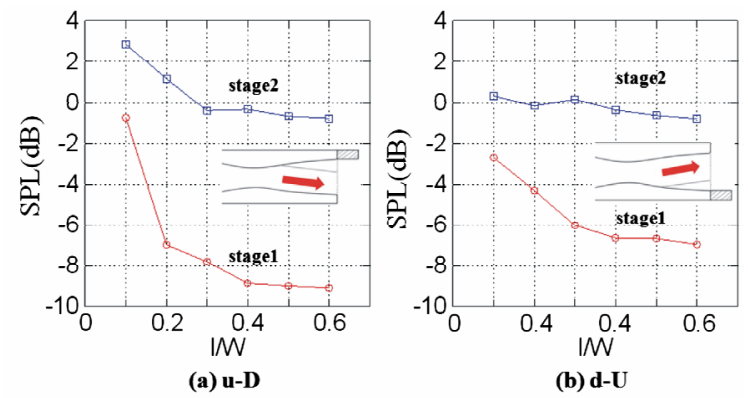

Figure 8. Variation of reduction amount of transonic resonance with various nozzle-lip lengths at 1.8 NPR. 


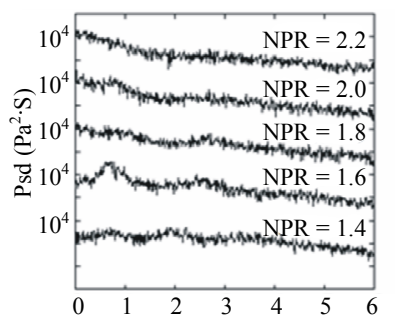

(a) $12 \mathrm{u}-\mathrm{D}$

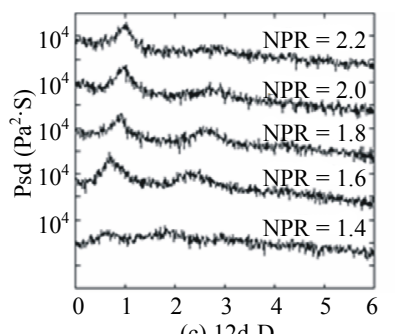

(c) $12 \mathrm{~d}-\mathrm{D}$

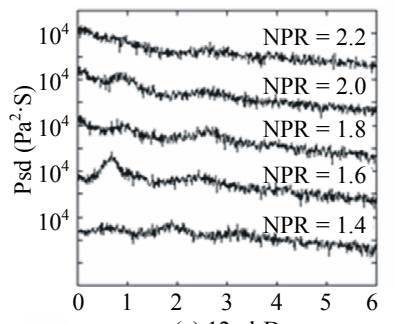

(e) 12ud-D

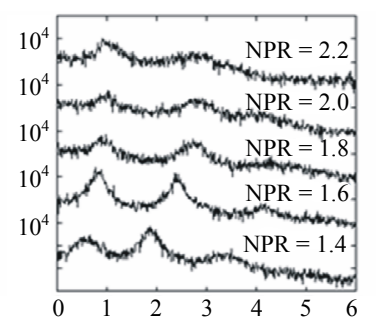

(b) $12 \mathrm{u}-\mathrm{u}$

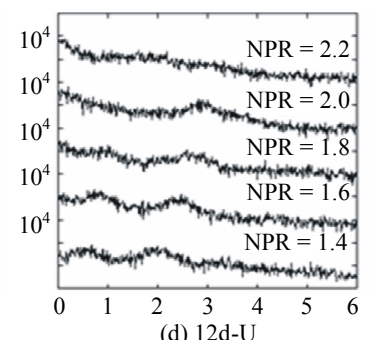

(d) $12 \mathrm{~d}-\mathrm{U}$

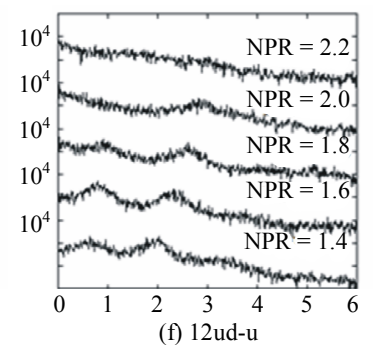

(f) 12ud-u
Figure 9. Variation of power spectral density of wall static pressure oscillation in case of $\mathbf{1 2} \mathbf{~ m m}$ nozzle-lip length.
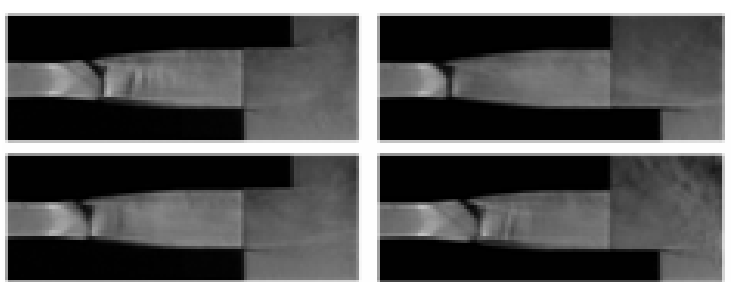

(a)
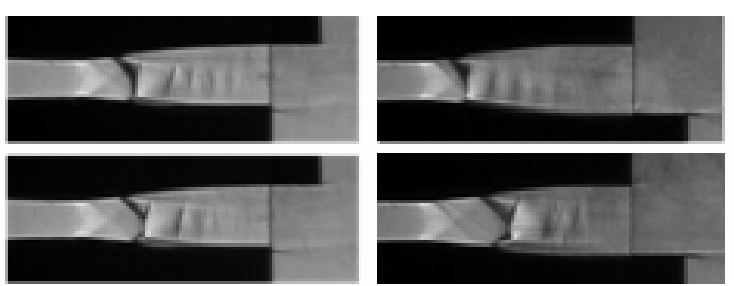

(b)
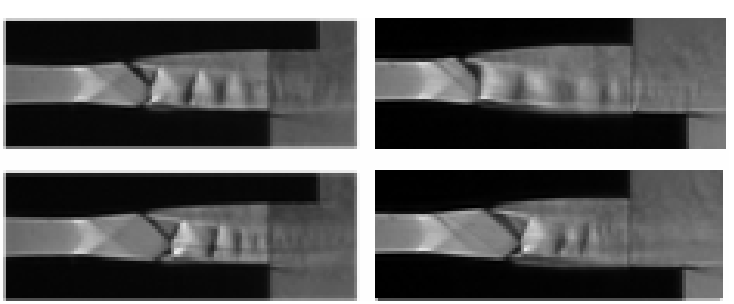

(c)

Figure 10. Schlieren images for typical nozzle pressure ratios (12 mm nozzle-lip length). (a) 1.6 NPR; (b) 1.8 NPR; (c) 2.0 NPR.
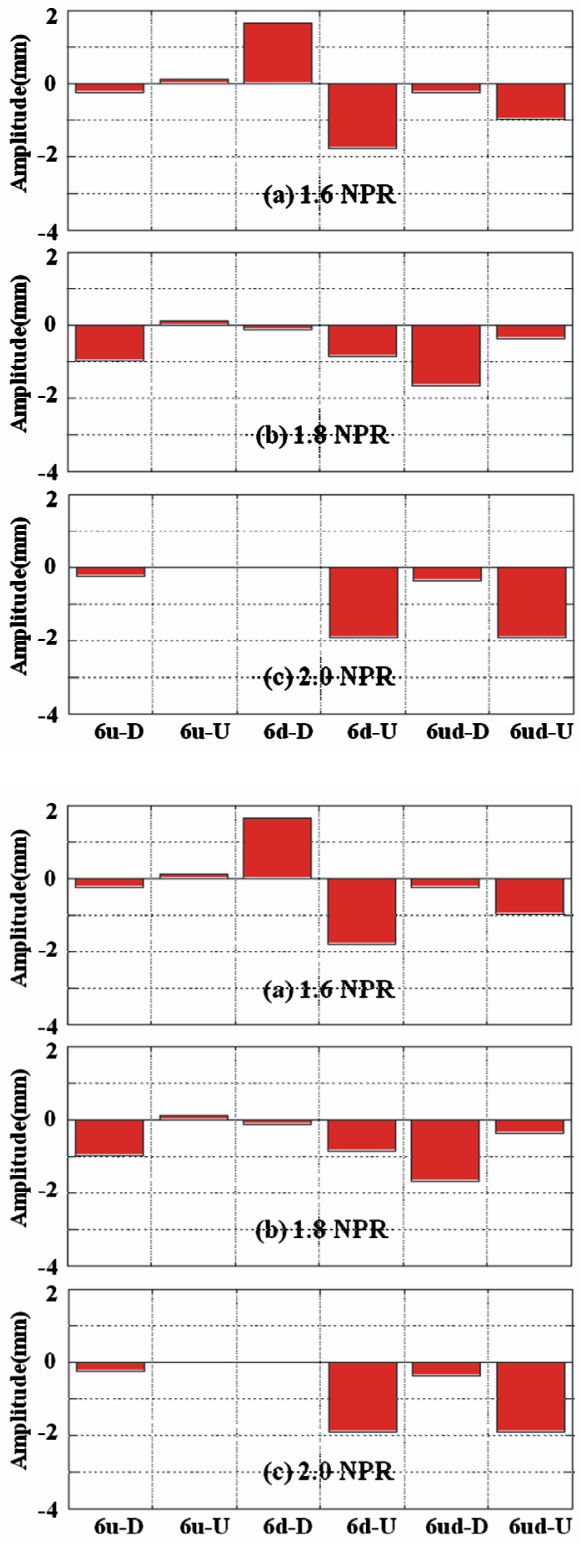

Figure 11. Amplitude comparison of oscillating first shock wave.

length and nozzle pressure ratios.

And the conclusions are summarized as follows: The transonic resonance was reduced about $5 \mathrm{~dB}$ in stage 1 when the large separation zone located at the side, where the nozzle-lip was attached additionally. And at that moment, power spectral density of the wall static pressure and the amplitude of first shock wave oscillation were also decreased.

\section{REFERENCES}

[1] C. K. W. Tam, "Supersonic Jet Noise," Annual Review of Fluid Mechanics, Vol. 27, No. 1, 1995, pp. 17-43. doi:10.1146/annurev.f1.27.010195.000313 
[2] K. B. M. Q. Zaman, M. D. Dahl, T. J. Bencic and C.Y. Loh, "Investigation of a Transonic Resonance with Convergent-Divergent Nozzles," Journal of Fluid Mechanics,
Vol. 463, No. 1, 2002, pp. 313-343.

doi:10.1017/S0022112002008819 